\title{
nature
}

14 February 2002 Volume 415 Issue no 6873

\section{Dangers of going underground}

Precautions need to be taken to protect researchers threatened by violent pressure groups. But open access to information and public accountability need to be sustained in the face of determined anti-rationality.

$\mathrm{F}$ aced with continuing attacks and threats from radical environmental and animal-rights groups, scientists increasingly find themselves lumped in with an odd assortment of societal targets - from fast-food restaurants to mink ranchers to secondhand car dealers - branded as agents of global capitalism and ecodestruction. No amount of academy studies proclaiming the safety of genetically modified (GM) crops, or protocols to guarantee the humane treatment of lab animals, or public-relations campaigns explaining the benefits of biotechnology to a hungry world, are likely to persuade the vandals and arsonists otherwise. They have reduced the world's complexity to a few simple manifestos, and have traded debate for intimidation.

So scientists should focus instead on winning over the vastly larger number of people who may be sceptical or uneasy about GM foods or the need for animal research, but who still have open minds. And the best way to do that is to stick with two of science's traditional strengths - the open exchange of information and a faith in rationality.

Two stories in this week's News section illustrate how difficult that high-minded road can be. A local planning board has rejected a proposal by the University of Cambridge to build a new primate research facility for fear of protests from animal-rights groups (page 725). And scientific societies are pressing the US agriculture department to remove information from the Internet about scientists who use laboratory animals - information that had been posted in the interests of transparency and public accountability (page 723).

The first action is the more lamentable, in that it represents a citizens' council simply caving in to bullying tactics. The second action, proposed by the research community itself, is defensible in spirit, but sets a worrying precedent. No one can blame scientists for wanting to protect themselves. The tactics of groups such as the Animal Liberation Front (ALF) and the Earth Liberation Front (ELF) have moved well beyond spray-painting slogans and trampling crops, to arson. If that trend continues, it's only a question of time before someone gets hurt. So the request from the Federation of American Societies for Experimental Biology (FASEB) to remove detailed identifying information about animal research facilities from the web seems justified. And there should be a way to accomplish that while still satisfying the public's right to know. The US agriculture department, for example, posts information about GM crop trials on the web, as does the Department for Environment, Food and Rural Affairs in the United Kingdom. In neither case is the precise location of research plots given, presumably to make things difficult for would-be saboteurs.

Some 'secrecy', if it can be called that, therefore seems warranted. At the same time, scientists must scrupulously avoid giving even the slightest impression of taking their research underground. That would only further inflame the zealots, and make it harder to win over the uncommitted. Besides, it's not clear that arsonists rely that much on the kind of information posted on the agriculture department website. Groups such as the ELF or ALF don't seem especially diligent about doing careful research before they choose their targets. More likely, a short news story about a genetics lab being built at a nearby university, or the simple knowledge that a scientist uses animals — any animals — in their work, will suffice.

Take the case of Toby Bradshaw, the University of Washington plant researcher whose office was burned down last May by the ELF. The arsonists obviously misunderstood his work. Bradshaw has studied traditional hybridization of poplar trees, but has never done any genetic 'engineering'. And when the eco-vandals fire-bombed his office, they also destroyed 100 showy stickweed plants - a quarter of the remaining samples of one of the region's most endangered species. Which goes to show that if too much information is sometimes dangerous, too little can be even worse.

\section{A boost too far?}

\section{Care will be needed over the proposed expansion of US bioterrorism research, lest the cure prove worse than the disease.}

t t should come as no surprise that President George W. Bush's "war budget" contains large new spending on research related to bioterrorism. The US government found itself in an untenable position after last autumn's anthrax attacks, unable to present a convincing case to the public that it knew what was happening, or how to respond. It couldn't tell postal workers what to do to protect their health or offer much advice on who else was at risk. If the attack had been sustained, it could have triggered mass panic in Washington and New York.

A government's first duty is to protect its citizens, and in those circumstances the United States has no choice but to invest heavily in bioterrorism research - if only to protect itself from future criticism. But this investment carries risks. As several researchers have already commented (see page 719), the rapid expansion of this activity will result in the circulation of more potentially dangerous materials and information to more people, even as the government attempts to restrict the flow of both. It has to be asked whether any new regulatory regime can be smart and flexible enough to contain this contradiction.

Additionally, questions will surely be asked about the ability of the National Institute of Allergy and Infectious Diseases (NIAID) to absorb a massive increase in its budget without wasting money on second-rate science. It will take more than the suave assurances of Tony Fauci, NIAID's director, to make a convincing case that such an expansion can be managed efficiently.

It now falls to Congress to consider the proposal and to craft the final budget numbers. For the reasons noted above, no one there is likely to oppose Bush's bioterrorism spending plans outright. But it is Congress's duty to scrutinize the budget carefully, even when the nation considers itself to be at war. It would be appropriate if somebody there has the guts to ask some tough questions about the national-security implications of the proposed expansion. 